\title{
E-COMMERCE: EXPERIENCIAS DE USUARIOS EN SUS COMPRAS POR INTERNET
}

\author{
E-COMMERCE: USER EXPERIENCES IN THEIR INTERNET \\ PURCHASE
}

\author{
Katherine Arroyave Jiménez ${ }^{1}$, Vinicio Cevallos Ponce ${ }^{2}$, Shirley Rosario Ponce Merino ${ }^{3}$, María \\ Leonor Parrales Poveda ${ }^{4}$
}

\author{
1 - Investigadora Independiente, Guayaquil, Ecuador \\ 2 - Universidad Católica Andrés Bello, Caracas, Venezuela \\ 3,4 - Universidad Estatal del Sur de Manabí, Manabí, Ecuador
}

1. Email: ing.arroyave.k@hotmail.com ORCID: https://orcid.org/0000-0002-1698-9576

2. Email: vinicio4874@hotmail.com ORCID: https://orcid.org/0000-0002-5056-5750

3. Email: shirley.ponces@unesum.edu.ec ORCID: https://orcid.org/0000-0003-2146-5045

4. Email: maria.parrales@unesum.edu.ec ORCID: https://orcid.org/0000-0003-3994-3711

Recibido: 11/05/2021 Aceptado: 21/07/2021

Para Citar: Arroyave Jiménez, K., Cevallos Ponce, V., Ponce Merino, S. R., \& Parrales Poveda, M. L. (2021). E-commerce: experiencias de usuarios en sus compras por internet. Revista Publicando, 8(31), 225-239. https://doi.org/10.51528/rp.vol8.id2246

\begin{abstract}
Resumen:
El artículo aborda como tema el análisis del e-commerce y las experiencias de los usuarios en sus compras por internet. El objetivo es demostrar que las prácticas de compras por internet posibilitan concebir, desde el punto de vista del comercio, una estrategia para optimizar las ventas de los negocios pequeños y medianos, así como establecer el equilibrio entre el carácter social e individual de los sujetos involucrados en el comercio electrónico, explicando su utilización, reducción de la desconfianza, ventaja y desventaja de su aplicación. El trabajo se sustenta en los fundamentos del materialismo dialéctico para contribuir al desarrollo de cualidades de la personalidad de compra y venta en correspondencia con la administración moderna y el comercio electrónico que está en pleno crecimiento. Se utiliza el estadístico Chi-cuadrado de Pearson para relacionar la dependencia de las variables del estudio. La experiencia, los cambios, retos, tendencias y competitividad de los mercados, así como los gustos y preferencias se afrontan como factores clave del comercio electrónico.
\end{abstract}

Palabras clave: comercio electrónico, competitividad, transacciones comerciales.

\begin{abstract}
:
The article addresses as a theme the analysis of e-commerce and the experiences of users in their online shopping. The objective is to demonstrate that Internet shopping practices enable to conceive, from the point of view of commerce, a strategy to optimize the sales of small and medium-sized businesses, as well as to establish the balance between the social and individual character of the subjects involved in e-commerce, explaining its use, reduction of distrust, advantage and disadvantage of its application. The work is based on the foundations of dialectical materialism to contribute to the development of qualities of the buying and selling personality in correspondence with the modern administration and the electronic commerce that is in full growth. Pearson's Chisquared test is used to relate the dependence of the variables of the study. Experience, changes, challenges, trends, and competitiveness of markets, as well as tastes and preferences are faced as key factors of e-commerce.
\end{abstract}

Keywords: electronic commerce, competitiveness, commercial transactions. 


\section{INTRODUCCIÓN}

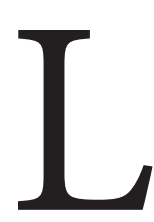
a situación actual que vive el mundo por la pandemia del virus de la Covid-19, ha obligado a muchos negocios a reflexionar sobre el modelo en que opera; este momento demanda de los dueños de empresas a utilizar mecanismos paralelos para hacer llegar el producto al consumidor final y lograr colocar su mercadería o servicio para seguir manteniéndose en el mercado y conservar su posicionamiento como marca.

En la Provincia de Manabí existen diversos negocios y franquicias de inversión nacional e internacional, que le apuestan a estos cantones, para que los sectores económicos a los que pertenecen se desarrollen, impulsando la reducción del desempleo y dinamismo en el aparato productivo. La mayoría de estos comercios ofrecen diversos productos y servicios que satisfacen las necesidades y deseos de los clientes; cada uno de ellos implementan nuevas ventajas competitivas constantemente para enfrentar la competencia que cada día es mayor.

Una de las limitantes que presentan los negocios locales es la falta de cultura de los empresarios, muchos aun en estos tiempos de pandemia por SARS-Cov-2, ofreciendo un mercado para usuarios que en su mayoría solo compran con efectivo, haciendo sus compras de forma directa y sin utilizar las facilidades que ofrece el comercio electrónico en la simplificación de tiempo y espacio para hacer transacciones de compraventa.

Es por esto que, al ver la alta competitividad de algunos negocios, los comerciantes deben actualizarse y utilizar el e-commerce como una estrategia que les permita mantener y aumentar sus ventas, evitando que los grandes supermercados o negocios de afuera, se lleven las utilidades generadas en un cantón en particular.

En ese sentido, Rodríguez et al. (2020) en el artículo titulado "El e-commerce y las Mipymes en tiempos de Covid-19" destacan que la Covid-19 ha desafiado al sistema socioeconómico mundial y las Mipymes ecuatorianas, afectadas por la paralización de sus actividades productivas debido a la contracción de la demanda por confinamiento social, forzó a repensar sus modelos de negocio. El impacto del e-commerce en las Mipymes por la disrupción de la pandemia permitió conocer que el comercio tradicional pasó a ser una estrategia de segundo plano, y el comercio electrónico una de las industrias ganadoras.

En este sentido el e-commerce es visto como una moderna metodología que da respuesta a varias necesidades de empresas y consumidores, como reducir costes, mejorar la calidad de productos y servicios, acortar el tiempo de entrega (Dans, s.f., pág. 1), lo que beneficiaría a la provincia de Manabí, porque una gran parte de la población prefiere ir a ciudades grandes como Guayaquil y Quito por ejemplo, a realizar sus compras, debido a que ofrecen mejores opciones y medios de pago que se adaptan a sus necesidades.

Por esto es que se debe implementar el uso del e-commerce en esta Provincia para favorecer tanto a compradores como vendedores y al Estado, debido a las contribuciones que recibiría a través del pago de impuestos.

En la actualidad, aun son pocos los negocios que emplean este sistema que ofrece atención las 24 horas del día, los 365 días del año, donde se 
pueden adquirir productos desde casa, ya sea a través de un Smartphone, laptop o cualquier medio tecnológico que permite acceder a internet, aumentando las ventas, porque mediante el ecommerce las distancias no son una barrera para adquirir algún producto. Personas de otros cantones incluso podrían adquirirlos sin necesidad de trasladarse al lugar donde está ubicado el negocio, ya que se contaría con medios de entrega rápida, seguros y de confianza, dinamizando la economía y el desarrollo de la Provincia.

Asimismo, hay que tener presente que, para seguir en el mercado, todo negocio debe estar dispuesto a innovar y emprender en lo novedoso. Día a día se realizan innovaciones para ofrecer un mejor servicio y rapidez para atender al cliente. Anteriormente utilizar esta medida de compra y venta por internet era casi imposible, porque los costos de las comunicaciones y el acceso a la internet eran sumamente altos o no se podía acceder a este servicio en todos los lugares. Gracias a los avances actualmente se tiene acceso al mundo tecnológico de una manera mucho más fácil, lo que sin duda alguna es un gran avance para penetrar comercialmente en un mundo globalizado.

$\mathrm{Y}$ es, en esa tendencia emprendedora en donde la tecnología juega un papel importante. A saber, de Sornoza Parrales et al. (2018):

Los emprendimientos crecen gracias a un proceso dual de tomar la cuota de mercado de los proveedores existentes y de incrementar la demanda general de los productos ofrecidos en el mercado. Por tanto, el proceso de destrucción creativa está basado en esfuerzos dinámicos y deliberados para cambiar las estructuras de los mercados y puede propender a la generación de innovaciones adicionales y oportunidades de rentabilidad (p.15).

Es así como, sobre emprendimiento e innovación y su impacto en el desarrollo económico de los negocios, las aportaciones de Josept Schumpeter se constituyen en verdaderos aportes teóricos para afirmar que el e-commerce ha hecho que las empresas cambien sus métodos tradicionales de venta, obligando a los gerentes a entrar en la nueva era del comercio para que puedan cruzar fronteras, mejorando y agilizando sus procesos de ventas y en efecto crecer en el mercado. De eso se desprende, considerar la innovación como un proceso que consiste en poner en práctica inventos previos de cualquier naturaleza o aplicación de la invención a usos industriales y comerciales, señalando que los emprendedores deben ser innovadores destacando por su perseverancia y su ambición (Schumpeter, 1934).

Se hace necesario resaltar, que tanto emprendedores como habitantes no están acostumbrados al uso del e-commerce, innovación y nuevas formas de llegar con un producto al mercado, porque no son métodos que se utilicen frecuentemente, lo que lleva a formular interrogantes como ¿Puede ser el e-commerce una buena estrategia para comercializar y vender productos y servicios en la provincia de Manabí?

\section{MÉTODOS Y MATERIALES}

Bajo un enfoque dialéctico-materialista, se hace uso de métodos teóricos y empíricos. Entre los métodos de carácter teórico se utiliza el análisissíntesis para realizar las críticas pertinentes a la 
literatura especializada y relacionada con el comercio electrónico, en la interpretación de los resultados del diagnóstico del estado actual del problema y de las conclusiones parciales y generales. Se usó el método de induccióndeducción, para llegar a conclusiones precisas acerca de cómo se desarrolla el objeto de estudio que para nuestro caso es el e-commerce y las experiencias de los usuarios a partir de los criterios expuestos por los autores consultados como Josept Schumpeter, donde afirma que el ecommerce ha hecho que las empresas cambien sus métodos tradicionales de venta, obligando a los gerentes a entrar en la nueva era del comercio para que puedan cruzar fronteras, mejorando $y$ agilizando sus procesos de ventas y en efecto crecer en el mercado y sistematización en la determinación de dimensiones e indicadores para evaluar el proceso y los resultados que se obtienen en los sujetos.

Se aplicó la técnica de la encuesta a 280 usuarios de compras por internet, muestra seleccionada de una población de 1.030.176 personas correspondientes a los cantones de la provincia de Manabí.

Tabla 1

Población urbana por cantones.

\begin{tabular}{lll}
\hline Provincia & Cantones & Población \\
\hline Manabí & Portoviejo & 223.086 \\
& Calceta & 33.415 \\
& Chone & 74.906 \\
& El Carmen & 77.743 \\
& Flavio Alfaro & 18.536 \\
& Jipijapa & 49.076 \\
& Manta & 221.122 \\
& Montecristi & 67.842 \\
& Paján & 12.266 \\
& Pichincha & 17.416 \\
& Rocafuerte & 33.469 \\
& Santa Ana de vuelta larga & 22.298 \\
& Bahía de Caráquez & 26.112 \\
& Tosagua & 28.174 \\
& Sucre & 13.426 \\
& Pedernales & 33.640 \\
& Olmedo & 9.844 \\
& Puerto López & 10.928 \\
& Jama & 23.253 \\
& Jaramijó & 18.486 \\
& San Vicente & 15.138 \\
& & $\mathbf{1 . 0 3 0 . 1 7 6 , 0 0}$ \\
\hline
\end{tabular}

Fuente: INEC censo 2010. 
Una vez obtenido los resultados de la aplicación de la encuesta se entraron al programa estadístico IBM-SPSS versión 25. Posterior a esto, se obtuvieron los datos descriptivos de las variables y se usó la medida estadística de correlación Chi-cuadrado de Pearson para ver cómo se relacionan las variables estudiadas.

\section{RESULTADOS}

En la provincia de Manabí, el rubro en el que se agrupan la mayoría de los negocios es en el sector comercio al por mayor y al por menor con un promedio de 1 a 5 años. En su mayoría se dedican a la comercialización de productos para el hogar línea blanca (neveras, cocinas, ventilador, colchones), otros enfocados en la línea negra (tv, equipos de sonido, reproductor DVD, celulares), negocios dedicados a la papelería (impresiones, productos de papelería, artículos de cómputo como teclados, parlantes, memoria USB).

Estos negocios en su mayoría no cuentan con una página web para comercializar sus productos o servicios, y los que sí tienen una página web, sólo la tienen para darse a conocer en el mercado y ofrecer promociones, pero no para realizar la compra directamente a través de su página web como es el caso de La Ganga, Artefacta, Marcimex entre otras marcas. El beneficio sólo ha sido para darse a conocer y ofrecer sus productos, promociones especiales por alguna fecha determinada, incrementando sus ventas, pero en sus locales físicos.

Entre los métodos que utilizan en la página web para promocionar $\mathrm{y}$ vender sus productos $\mathrm{o}$ servicios los negocios que la poseen utilizan fechas especiales como día de la madre, día del padre, feriados, fin de mes, día del amor y la amistad, cuando llega alguna mercadería nueva y quieren darla a conocer al mercado promocionándola con un descuento en especial.

A todos les gustaría aplicar el e-commerce con el objetivo de aumentar el volumen de ventas, de globalizarse y ofrecer una nueva forma de compra a sus clientes, aumentando su fidelidad y posicionamiento de marca. Para lograrlo, necesitan ofrecer el servicio de pago a través de tarjetas de créditos como medio de pago de sus clientes. Al respecto, sólo algunos de los negocios las utilizan, en su mayoría utilizan el pago a cuotas porque de esta manera se les facilita más a las personas poder adquirir algún producto. Negocios como Comercial Osejos, La Ganga, Marcimex, Comercial Morán Parrales sí utilizan como medio de pago las tarjetas de crédito, lo que les ha dado más confianza en la transacción tanto al comprador como al vendedor porque así ambos tienen un respaldo de que su pago se va a realizar en los tiempos establecidos.

El e-commerce es un medio de venta positivo, porque al abrir una página web le da la posibilidad a la empresa de ampliar su cobertura con el uso de menos recursos, evitando el pago de renta del local/servicios y sueldos. Ofrecerían a sus clientes otra forma de pago. También porque por medio de la página web realizarían la publicidad de sus productos minimizando costos en relación con comunicación tradicional. Al comprar y vender por la página web, los productos y servicios estarán al alcance de los consumidores a cualquier hora los 365 días del año, teniendo un mayor alcance de público.

Aunado a esto, las encuestas realizadas a los consumidores describen que al $58 \%$ sí realizaría 
compras por internet porque ven en esta opción, mayor seguridad y confianza al momento de realizarlas. El 42\% no lo haría por algunas razones como: temor a ser estafado, no les llama la atención o porque simplemente no manejan la tecnología.

\section{Figura 1}

Compras por internet.

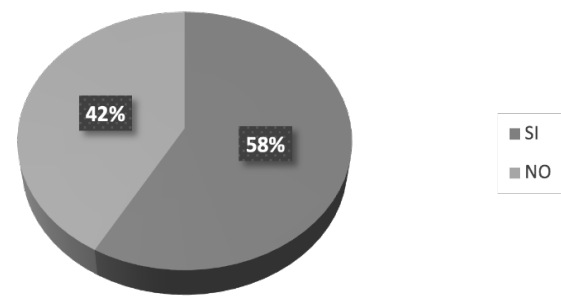

Fuente: Elaborado por autores.

Comprar por internet no sólo ofrece al usuario una gran variedad en el número de tiendas y productos. Los métodos de pago disponibles en el comercio electrónico son cada vez más numerosos y seguros y el comprador puede realizar el pago de la manera que le resulte más cómoda o conveniente, incluso ya es posible pagar con la huella dactilar. Ya sea utilizando tarjeta de crédito o débito, realizando una transferencia bancaria o pagando a través de una pasarela de pago como PayPal, las posibilidades entre las que puede elegir el cliente son cada vez más numerosas (Santofimia, 2015).

En cuanto a la seguridad que el comprador tiene al realizar compras a través de internet, en escala del 1 al 10 se observa que el $18 \%$ de las personas encuestadas tiene una seguridad de 8 ; $17 \%$ de $9 ; 16 \%$ de $10 ; 13 \%$ de $7 ; 10 \%$ de $1 ; 10 \%$ de 2; $4 \%$ de $5 ; 6 \%$ de $3 ; 3 \%$ de $4 ; 3 \%$ de 6 .
Figura 2

Seguridad de compras por internet

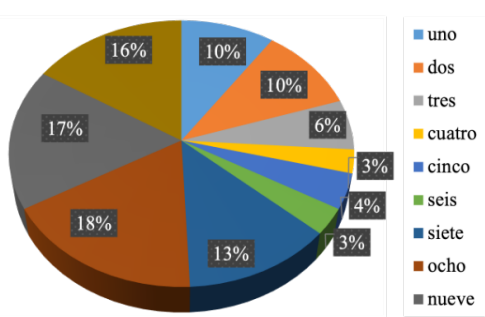

Fuente: Elaborado por autores.

De acuerdo con los resultados el 64\% correspondiente a las opciones entre 7 y 10 puntos sienten seguridad al realizar compras por internet y su deseo de adquirir productos o servicios por este medio porque consideran que es seguro. La empresa de pagos WorldPay realizó un estudio denominado Online Payments Journey a 1.500 compradores online y revisó las páginas web de 150 comercios y agencias de viajes de Brasil, Chile y México en donde muestran que la seguridad es el tema más importante para el público latinoamericano cuando se trata de compras o viajes online. El estudio destaca la importancia que los consumidores le otorgan a la seguridad: $60 \%$ de los compradores online se sienten más seguros cuando la tienda virtual exhibe los logos de certificación digital y autenticación del pago en su página inicial (Infochannel info, 2015).

$\mathrm{Al}$ abordarse si actualmente ha realizado compras por internet. El 56\% afirman que han realizado compras por internet, poseen una tarjeta de crédito y ven en ella mayor seguridad en sus compras, facilidad de pago, menor tiempo empleado en realizar la compra, más confiable e incluso más económico, mayor variedad y mayor comodidad. Un $44 \%$ no ha realizado compras por internet, tienen temor a ser estafados o 
simplemente porque no tiene un respaldo económico para que un banco les proporcione una tarjeta de crédito.

\section{Figura 3}

Compras realizadas por internet

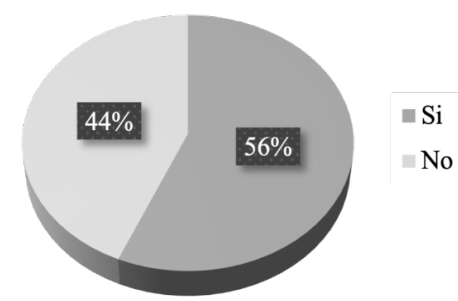

Fuente: Elaborado por autores.

En relación con las páginas utilizadas para realizar sus compras se observa que el $25 \%$ no hace compras a través de ellas. El 32\% realizan compras en la página OLX; 22\% en Amazon; 12\% en Wish; $7 \%$ en eBay; 6\% Aliexpress; 5\% Alibaba y 10\% otras, concluyendo que sí existe un gran porcentaje de personas que utiliza el e-commerce para hacer compras.

\section{Figura 4}

Compras realizadas en páginas web

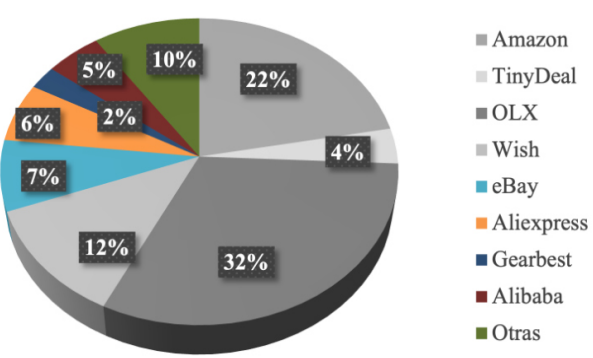

Fuente: Elaborado por autores.

En la actualidad hay un sinnúmero de páginas web que permiten que se realice compras por internet, ofreciendo a los consumidores un método mucho más rápido sin tener que desplazarse hacia el local de donde desean el producto o servicio, incluso traspasando fronteras porque se puede realizar compras internacionalmente en sólo minutos.

Las páginas para comprar por internet se multiplican año tras año, lo que puede dificultar la búsqueda para el usuario. Los consumidores online exigen claridad, transparencia, buena oferta y seguridad del pago. Son los centros comerciales del e-commerce, donde se vende todo tipo de productos y también servicios como hoteles, viajes o actividades. Las 4 páginas más grandes para comprar por internet son: Amazon, de las páginas para comprar por internet, es la que mayor número de usuarios tiene; ebay, le sigue en popularidad a Amazon, esta web es conocida por disponer de tres modalidades diferentes de pago para sus usuarios subasta, cómpralo ya, anuncio clasificado; Aliexpress es el "buque insignia chino" su ventaja competitiva es el precio; Google Shopping esta plataforma está más enfocada en la comparativa de precios web (Observatorio Ecommerce y transformación digital, 2016).

Al mismo tiempo, al preguntarles si realizan compras utilizando tarjetas de crédito, el 47\% afirmó que sí porque pueden adquirir los productos o servicios que desean, porque no en todas las ocasiones se tiene dinero en efectivo para adquirirlas y estas tarjetas dan la posibilidad de pagar en cómodas cuotas. Un 53\% no utiliza las tarjetas de crédito como medio de pago porque no la tienen o porque no les gusta adquirir deudas y se abstienen de comprar cuando no hay dinero en efectivo.

Al elegir la opción de comprar con tarjeta de crédito, se divide el valor de la compra al plazo que se acuerde entre el establecimiento y el cliente. Hay locales comerciales que ofrecen diferir una deuda 
sin intereses, lo que resultará conveniente, pero hay otras que no tienen ese beneficio y deben tener en cuenta el adicional por intereses (Rovayo y Acosta, 2016).

Figura 5

Compras con tarjeta de crédito

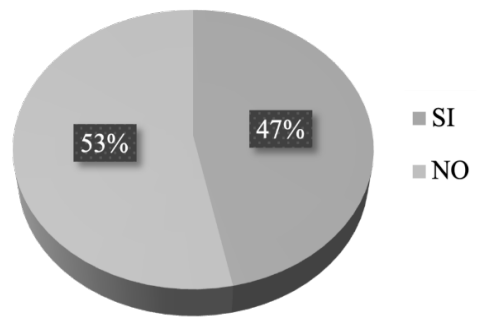

Fuente: Elaborado por autores.

En ese mismo contexto, al preguntar qué productos con frecuencia adquieren vía online, el $27 \%$ de las personas ha adquirido ropa, un $21 \%$ tecnología, $16 \%$ calzado, $14 \%$ accesorios, $11 \%$ cosméticos, $8 \%$ joyas y un $3 \%$ adquiere comidas (Véase Figura 6).

\section{Figura 6}

Productos adquiridos por internet

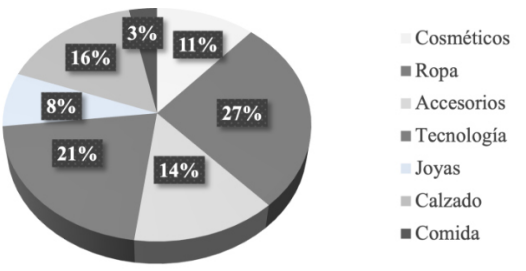

Fuente: Elaborado por autores.

De acuerdo con los resultados de esta encuesta se ve reflejado que a una gran parte de la población les gusta adquirir productos a través de internet por la comodidad de hacerlo desde sus hogares en sólo minutos, incluso también hacen pedido a domicilio de comidas rápidas. En un estudio de mercado e-commerce, por parte de la empresa
Linio Ecuador, se determinó que el 74\% de los compradores en línea prefiere artículos tecnológicos. Otras categorías que lideran los gustos de los ecuatorianos con salud y belleza y ocupan un lugar secundario en la atención de los clientes moda, estilo de vida y hogar. Entre los dispositivos más solicitados por los compradores están los Smartphone y las tablets (El Telégrafo, 2016).

Vinculado a esto, los lugares en donde han adquirido alguno de los productos, el $41 \%$ realiza compras en las grandes ciudades como Guayaquil; 3\% Quito; 15\% en EEUU; 12\% en China; 3\% Colombia; $1 \%$ México. Un 9\% Portoviejo; 8\% Manta; 2\% Jipijapa, 1\% Montecristi; 2\% Santo Domingo y 1\% Paján.

\section{Figura 7}

Lugares donde se adquirieron productos

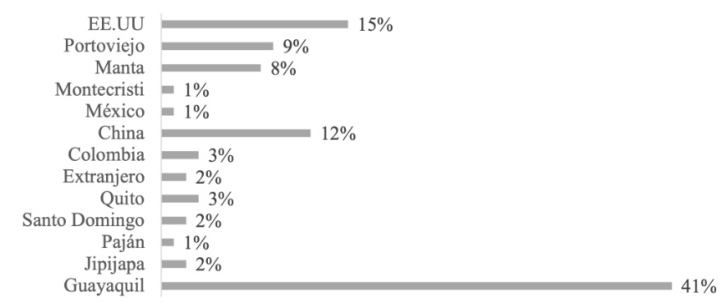

Fuente: Elaborado por autores.

En una de las principales ciudades del país como lo es Guayaquil, se puede observar que gran cantidad de la población, se desplaza hasta allá para realizar sus compras porque hay más variedad de locales y de productos, porque están las marcas que ellos prefieren y en su mayoría los comerciales ofrecen la opción de pago mediante tarjeta de crédito dando una mayor facilidad de pago. También acceden a las compras en el exterior a través de páginas web, donde las envían directamente al hogar y un porcentaje menor en 
ciudades de la provincia de Manabí que, aunque hay varios comerciales que usan pago mediante tarjeta de crédito, no todos la emplean trayendo como consecuencia que los consumidores se trasladen a las principales ciudades de Ecuador.

Según el estudio de GlobalWebIndex (GWI) los países que tienen el mayor porcentaje de usuarios que compran por internet son: China $75 \%$, Alemania $72 \%$, Corea del Sur $72 \%$, India $71 \%$, Brasil 67\%, Reino Unido 67\%, Irlanda 66\%, Turquía 64\%, Taiwán 63\%, Indonesia 62\% (Forbes, 2015).

A nivel de compradores móviles son: México 35,6\%, Colombia 33,8\%, Chile 33,5\%, Perú 31,5\% y Argentina 22\% (América Economía, 2017).

El 51\% de las compras virtuales se realiza en las tres ciudades más grandes del país: Quito, Guayaquil y Cuenca. Así lo dio a conocer el Instituto Ecuatoriano de Estadísticas y Censos (INEC) en el e-commerce day, evento dedicado a la difusión del comercio electrónico (Durán, 2014).

Cuando se indagó sobre qué otros productos quisiera que se ofrecieran por internet, el $31 \%$ de las personas encuestadas no escogió ninguna de las opciones propuestas de otros productos que se puedan ofrecer por internet, en cambio un 7\% eligió productos de la canasta básica, $7 \%$ medicina, $7 \%$ papelería, $6 \%$ comida rápida, $5 \%$ productos de uso personal, $5 \%$ tecnología, $5 \%$ vehículos, $4 \%$ de ellos opinan que ya se ofrece de todo por internet, 4\% ropa, 4\% artículos para el hogar, 3\% línea blanca, $3 \%$ boletos de viaje, $2 \%$ mascotas y productos, $2 \%$ juguetes, $1 \%$ vivienda, $1 \%$ materiales de construcción, $1 \%$ árboles, proporcionando una amplia lista de productos que desean que se les ofrezca por internet para realizar compras.

Actualmente se observa que la tecnología es un medio que permite realizar diversas actividades sin tener que movilizarse el comprador. Diversos consumidores desean que, por medio de éste, se les ofrezca todos los productos que ellos requieren para su uso porque consideran que no todo los pueden adquirir por este medio, dando opciones de los posibles productos o servicios que se puedan ofrecer en un futuro. Según los resultados el $27 \%$ desea adquirir productos de la canasta básica, medicina, papelería y comida rápida. Hay personas que desconocen que por medio del internet se pueden adquirir boletos de viaje.

Ecuador mueve al año USD 200 millones en ventas en línea, según el Instituto Latinoamericano de Comercio Exterior. En cambio, las cifras INEC son superiores y señalan que en el país se generan USD 540 millones. Esos números reflejan el aporte de las tiendas virtuales en las actividades comerciales en el país y que abarcan productos como electrodomésticos, ropa de diseñadores, zapatos, productos mecánicos cuyas ventas se apoyan en la Internet (Líderes, s.f.).

Al investigar si les gustaría comprar comida rápida por internet al $52 \%$ de las personas encuestadas, sí les gustaría comprar comida rápida por internet porque hoy en día las personas tienen menos tiempo para trasladarse a un restaurante o local donde puedan comprar comida rápida porque su trabajo se los impide, por eso se ofrece esta alternativa de vender comida rápida a través de internet, lo cual le facilitaría la compra a aquellas personas que su tiempo es limitado, llevándoles a su domicilio o lugar de trabajo el 
pedido. El otro 48\% no la compraría.

Con el objetivo de brindar un servicio fácil, rápido y sin ningún costo adicional, adomicilioYa.com ofrece cerca de 250 opciones de restaurantes en Quito, Guayaquil y Cuenca para pedidos de comida on-line. La plataforma, según un comunicado, fue el resultado de un emprendimiento ecuatoriano que se inició en el 2012 con el nombre DeliYami, que fue adquirido por la multinacional hellofood, en agosto de 2014. (El Universo, 2016).

\section{Figura 8}

Comprar comida rápida por internet

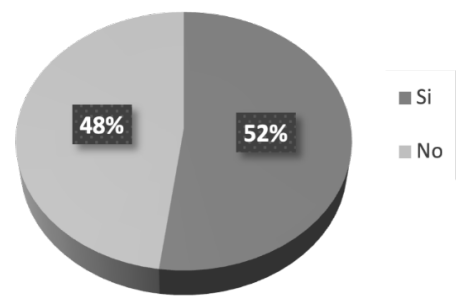

Fuente: Elaborado por autores.

Considerando la comunidad o lugar donde vive el usuario, hay negocios que emplean internet como medio de venta, el encuestado en un 33\% expresa que los negocios cerca de su comunidad o lugar donde viven sí emplean internet como medio de venta y un $67 \%$ que no lo emplean.

Algunos locales comerciales no utilizan la opción de ofrecer a sus clientes un pago por medio de la tarjeta de crédito, porque no tienen el pleno conocimiento de cómo hacerlo o porque no ven en este medio de pago, una opción para sus negocios, pero están totalmente equivocados, porque es una forma de expandirse y obtener mejores ingresos a través del pago de la tarjeta de crédito. Un factor que influye también, es el pago por la transacción que cuanto a negocios pequeños se refiere porque debe adicionarse al consumidor final.

El $17,1 \%$ de las empresas realizaron alguna transacción comercial a través de internet en Ecuador en el 2014 frente al 16,8\% del 2013, según datos del Módulo de Tecnologías de la información y la Comunicación (TIC), publicado por INEC. Del total de empresas investigadas, el $8,4 \%$ de las empresas vendieron sus productos a través de la red, mientras el 14,6\% hicieron alguna compra; frente al $8,7 \%$ y $14 \%$ del 2013 respectivamente (INEC, 2016).

\section{Figura 9}

Negocios que emplean internet como medio de venta

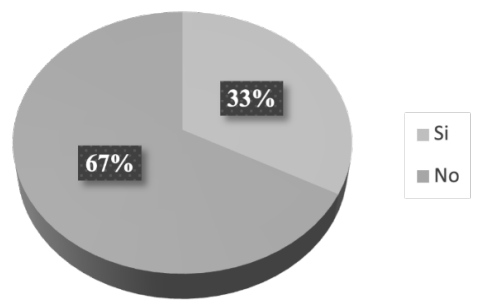

Fuente: Elaborado por autores.

Cuando se preguntó si les gustaría que los negocios en los que habitualmente realizan compras, ofrezcan sus productos también por internet con servicio de entrega a domicilio, al $76 \%$ de las personas encuestadas, sí les gustaría que ofrezcan la opción de realizar sus compras mediante internet; el $24 \%$ quiere seguir adquiriendo sus productos de forma tradicional. Las personas actualmente tienen mayor confianza al comprar por internet, porque hay mayor seguridad cuando se compra utilizando una tarjeta de crédito, sin correr el riesgo de sufrir algún tipo de robo. También desean que los lugares que frecuentan, les ofrezcan un servicio de delivery, 
$\begin{array}{lllllll}\text { R } & \text { E } & \text { V } & \text { I } & \text { S } & \text { T } & \text { A }\end{array}$

porque este da más facilidades al consumidor. Sin embargo, también hay personas que prefieren comprar personalmente en los locales comerciales.

De acuerdo con Gianfranco Baquero, Country Manager de adomicilioYa.com, esta es una plataforma líder en pedidos de comida a domicilio en línea. Las empresas en la actualidad utilizan internet como un canal de ventas, sustituyendo las visitas personales, correo y teléfono por pedidos electrónicos, dando paso al comercio electrónico, conocido como e-commerce. Además, existe una tendencia muy marcada a la creación de emprendimiento cuya finalidad es ofrecer la venta de un producto o servicio únicamente a través del internet para facilitar la vida de los usuarios como ahorro de tiempo y desde la comodidad de sus hogares u oficinas (Confimado.net, 2016).

\section{Figura 10}

Compras por internet de los negocios que habitualmente realizan compras

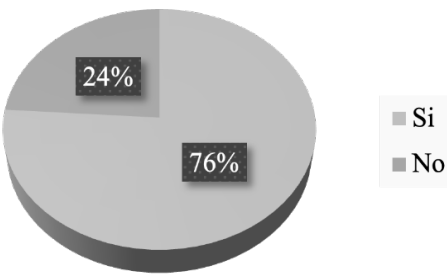

Fuente: Elaborado por autores.

Para medir si existe relación entre las variables se establece la tabla cruzada y el estadístico Chicuadrado de Pearson a continuación:

Tabla 2

Tabla cruzada ¿Considera seguro realizar compras por internet? ¿ ¿Realizaría compras por internet?

\begin{tabular}{|c|c|c|c|c|c|}
\hline & & & \multicolumn{2}{|c|}{$\begin{array}{c}\text { ¿Realizaría compras } \\
\text { por internet? }\end{array}$} & \multirow{2}{*}{ Total } \\
\hline & & & Sí & No & \\
\hline \multirow{4}{*}{$\begin{array}{l}\text { ¿Considera } \\
\text { seguro realizar } \\
\text { compras por } \\
\text { internet? }\end{array}$} & \multirow[t]{2}{*}{ Sí } & Recuento observado & 158 & 0 & 158 \\
\hline & & Recuento esperado & 92 & 66 & 158 \\
\hline & \multirow[t]{2}{*}{ No } & Recuento observado & 5 & 117 & 122 \\
\hline & & Recuento esperado & 71 & 51 & 122 \\
\hline \multirow[t]{2}{*}{ Total } & & Recuento observado & 163 & 117 & 280 \\
\hline & & Recuento esperado & 163 & 117 & 280 \\
\hline
\end{tabular}

Tabla 3

Pruebas de chi-cuadrado ¿Considera seguro realizar compras por internet? ${ }^{*}$ Realizaría compras por internet?

\begin{tabular}{lccc}
\hline & Valor & df & $\begin{array}{c}\text { Significación } \\
\text { asintótica } \\
\text { (bilateral) }\end{array}$ \\
\hline Chi-cuadrado de Pearson & & 158 & 158 \\
Corrección de continuidad (b) & 117 & 122 & 122 \\
Razón de verosimilitud & 51 & 122 & 122 \\
Asociación lineal por lineal & 117 & 280 & 280 \\
N de casos válidos & 117 & 280 & 280 \\
\hline
\end{tabular}

Nota: a. 0 casillas (,0\%) han esperado un recuento menor que 5. El recuento mínimo esperado es 50,98. 
Como resultado obtenido en el análisis sobre correlación, se establece que con un nivel de significancia de $0,000<0.05 \%$ existe relación de dependencia entre las compras online $y$ las experiencias de los usuarios. Existen factores que inciden en la compra por internet, tal es el caso de la seguridad, al tener el usuario mayor confianza aumenta la decisión de comprar por internet. En cuanto al tiempo empleado al momento de efectuarlas, el hecho de ser más fáciles y económicas ya que no implica salir de casa para comprar, son algunos factores que hacen que las personas realicen compras habituales por internet. Por otro lado, existen las personas que a pesar de las bondades que ofrece el poder comprar desde la comodidad de los hogares a través del e-commerce no lo hacen por temor a ser estafados, no están familiarizados con los métodos de compra y en la mayoría de los casos no saben cómo usar la tecnología para este tipo de situaciones o no tienen acceso a ella, pero en general el resultado es positivo porque el $58 \%$ sí realizaría compras por internet y a través de una mayor información y divulgación de conocimiento sobre cómo hacer las compras por internet este porcentaje irá mejorando gradualmente $y$ de esta forma se insertarán en el mundo globalizado donde hoy por hoy las compras por internet predominan.

\section{CONCLUSIONES}

Ecuador ha venido soportando enormes deficiencias en infraestructura de telecomunicaciones, de cultura y educación para impulsar el crecimiento de los mercados electrónicos, lo que representa una desventaja competitiva en el escenario mundial. Actualmente las insuficiencias van siendo disminuidas, a través de iniciativas aisladas tanto de parte del Gobierno
Nacional, (a través del desarrollo de proyectos de compras públicas, dinero electrónico, facturación electrónica, entre otros) como el sector empresarial. El e-commerce en Ecuador ha venido creciendo a un ritmo lento, debido a que los negocios en su mayoría, por el tamaño de sus estructuras, por su cultura organizacional, por el desconocimiento y por la desconfianza en el uso de la tecnología no le han dado el uso debido y oportuno. Ahora con la pandemia por la Covid-19, esta metodología ha tomado auge, pero aún hace falta mucho por hacer en cuanto al tema en el sector empresarial.

En ese sentido, la experiencia de los usuarios en las compras por internet es gradual en casi toda la provincia de Manabí. Un factor que influye es la falta de plena confianza en adquirir productos o servicios por internet, por temor a ser defraudados, por lo que utilizan canales de comercialización directos en sus compras y en efectivo, sin tener que usar las tarjetas de crédito.

El e-commerce como estrategia de venta, no es utilizado por los comercios en una gran mayoría. En algunos negocios de línea blanca, línea negra y productos en general hay cierta aplicación, pero en el mercado de comidas rápidas es prácticamente nulo el uso del e-commerce, solamente ofrecen sus productos de manera directa sin usar medios tecnológicos para aumentar sus ventas. El delivery, aún es limitado o tiene recargos en la compra.

Los usuarios que sí deciden adquirir productos o servicios por medio de páginas web, en su mayoría recurren a comercios extranjeros con páginas como Amazon, eBay, OLX, Wish entre otras, porque son plataformas reconocidas a nivel 
$\begin{array}{lllllll}R & \text { E } & \text { V } & \text { I } & S & T & A\end{array}$

Public a n d o

I S S N $13390-9304$

mundial y les han brindado seguridad, confianza, rapidez en la entrega, así como satisfacción en sus compras on-line.

Debido a la competencia agresiva actual, los comerciantes deben utilizar el e-commerce como una estrategia, donde se obtendrían diferentes ventajas como reducción significativa de sus costos operativos que se emplean en un negocio tradicional. Se reducen las brechas geográficas para los usuarios, consiguiendo comprar desde cualquier lugar. Los emprendimientos serían mucho más competitivos en un medio comercial altamente globalizado en donde la sombra de grandes multinacionales puede hacer desaparecer muchos pequeños negocios que aún no deciden interactuar en base a las tendencias de la época online, donde la virtualidad ha ganado espacio y el e-commerce es la respuesta a esas demandas del siglo XXI y en épocas de pandemia por el virus de la Covid-19. 


\section{REFERENCIAS}

América Economía. (13 de Abril de 2017). ¿Cuáles son los países que más compran desde móviles en Latinoamérica? https:// tecno.americaeconomia.com/articulos/ cuales-son-los-paises-que-mas-comprandesde-moviles-en-latinoamerica

Confimado.net. (14 de Mayo de 2016). Internet se ha convertido en una nueva vía para emprender y crecer los negocios. http:// www.confirmado.net/internet-se-haconvertido-una-nueva-via-emprendercrecer-los-negocios/

Dans, E. (s.f.). Comercio electrónico. http:// profesores.ie.edu/enrique_dans/download/ ecommerce.pdf

Durán C., M. (05 de Agosto de 2014). El comercio electrónico se concentra en Quito, Guayaquil y Cuenca. http://www.elcomercio.com/ tendencias/comercio-electronicoecommerce-emprendimiento-internet.html

El Telégrafo. (08 de Febrero de 2016). Obtenido de http://www.eltelegrafo.com.ec/noticias/ tecnologia/30/el-74-de-compras-online-esde-tecnologia

El Universo. (27 de Abril de 2016). Aplicación móvil facilita los pedidos de comida a domicilio. http://www.eluniverso.com/vida-estilo/ 2016/04/27/nota/5546724/aplicacion-movilfacilita-pedidos-comida-domicilio

Forbes. (04 de Junio de 2015). Los 10 países que más compran por Internet. https:// www.forbes.com.mx/los-10-paises-quemas-compran-por-internet/
Infochannel.info (2015). Compradores latinos dudan de seguridad online. Worldpay - Online Payments Journey- Helldorff, T. https:// www.infochannel.info/compradores-latinosdudan-de-seguridad-online

INEC. (21 de Diciembre de 2016). El 17,1\% de las empresas realizan comercio electrónico en Ecuador. http:// www.ecuadorencifras.gob.ec/el-171-de-lasempresas-realizan-comercio-electronico-enecuador/

Líderes. (s.f.). Las ventas online amplían el mercado. http://www.revistalideres.ec/lideres/ventason-line-amplian-mercado.html

Observatorio E-commerce y transformación digital. (2016). Obtenido de http:// observatorioecommerce.com/paginas-paracomprar-por-internet/

Rodríguez, K. G., Ortiz, O. J., Quiroz, A. I., \& Parrales, M. L. (2020). El e-commerce y las Mipymes en tiempos de Covid-19. Espacios, 41(42), 100-118. DOI: $10.48082 /$ espaciosa20v41n42p09

Rovayo, D., \& Acosta, D. (13 de Septiembre de 2016). Compras con tarjeta de crédito: ¿pagos en diferido o corriente? El Universo. http:// www.eluniverso.com/noticias/2016/09/13/ nota/5798622/compras-tarjeta-creditopagos-diferido-o-corriente

Santofimia, J. (7 de Septiembre de 2015). Comprar por internet. http://www.consumer.es/web/es/ tecnologia/internet/2015/08/19/222601.php

Schumpeter, J. A. (1934). The Theory of Economic 
$\begin{array}{llllllll}R & \text { E } & \text { V } & \text { I } & S & T & A\end{array}$

Public a n d o

I S S N $13390-9304$

Development Cambridge Mass, Harvard University Press.

Sornoza Parrales, D.; Parrales Poveda, M.; Sornoza Parrales , G.; Cañarte Rodriguez , T.; Castillo Merino, M.; Guaranda Sornoza, V., \& Delgado Lucas, H. (2018). Fundamentos de emprendiemiento (Primera ed.). Editorial Área de Innovación y Desarrollo,S.L. 